\title{
Cross-cultural experience as a source of attitude change ${ }^{1}$
}

JEANNE WATSON AND RONALD LIPPITT

University of Chicago and University of Michigan

National culture provides the framework for many attitudes toward one's own country and toward other countries. It seems reasonable to assume that travel in a foreign country with a different culture would have a significant impact on these attitudes. We were given an opportunity to examine this assumption when we were asked to evaluate the effect upon a small number of German visitors of their experience in the United States.

Briefly, our study was concerned with twenty-nine Germans who visited the United States for periods of six months or a year during the years 1949-51. The visitors were participants in a program financed by the United States Department of State, which brought young men and women to colleges and universities throughout the United States. The groups with which we became involved included six women and twenty-three men, ranging in age from twenty-two to thirty-six. They took part in a program which was under the supervision of the Political Science Department of the University of Michigan, and their time in this country was divided between seminars, courses, and field trips at the university and travel and individual internships away from the university.

1 Address delivered at the 65th Annual Convention of the American Psychological Association, New York, 1957.
The research program consisted primarily of a series of three interviews, administered in English shortly after the visitors arrived in Ann Arbor; shortly before they left the United States; and approximately six months after their return to Germany. These interviews were supplemented with paperand-pencil questionnaires and with direct observation and training. Information was obtained from the visitors about their attitudes toward Germany and America, their ideas about democracy, their ideas and attitudes related to democratization and the initiation of social change, and their relationships with people at home. There was also some exploration of their ideas about family and sex roles and their attitudes toward peers and toward authority. A detailed report on the findings of this study is presented elsewhere (2). In the present paper we shall not be concerned so much with reporting the findings as with using them to develop and illustrate some fairly general propositions about cross-cultural experience as a source of attitude change.

Perhaps the most general proposition we can suggest is that foreign visitors approach a new culture from the point of view of the old. This point reappears in every new study of cross-cultural education. Whenever a social scientist examines the experience of visitors to his own country, he is struck by the extent to which the reactions of the vis- 
itors are governed by their own national frame of reference. This is true whether the visitors are from Germany, as in our study, or from any other country. The situation of one country vis-à-vis the other focuses attention on certain areas in which the visitors can agree that it is desirable to learn from the host country and other areas in which they prefer to avoid accepting influence from their hosts. We may call this orientation which derives from the situation of one country in relation to another a cross-national perspective. The cross-national perspective of any foreign visitor supports two kinds of change. First, it favors learning new ways to implement values which are held in common by the two cultures. For example, the German visitors whom we knew placed a high value on individualism. They felt that this value was shared by Americans, and consequently they were willing to learn from Americans how to be more successfully individualistic. Two changes which seemed to grow out of this shared value were the development of more favorable attitudes toward the American pattern of raising children and toward the American style of tolerant give-and-take in interaction. The former change is particularly notable, since the original attitude of the visitors toward American patterns of child-rearing was quite negative.

A second way in which the cross-national perspective can facilitate learning is to define the host country as a relevant source of expert knowledge in certain limited areas. For instance, America may be viewed as having highly developed knowledge about industrial techniques or as having successfully achieved equality for women or, by the Germans in 1950, as being more expert than Germany in the day-to-day use of democratic procedures. Thus, for example, the Germans were much interested in American patterns of civic activity and anxious to see what they could learn from these that would apply to Germany.

The anticipation of the expertness to be found in the host country sometimes goes too far. If the visitor expects to find magical or miraculous solutions, he will be disappointed. Then his eagerness to learn from the host country may be converted into bitter disillusionment and a refusal to learn anything.

There are several ways in which cross-national perspectives can serve to block learning. The most important of these is the creation of what Lambert and Bressler in their study of Indian students on an American campus (1) have called "areas of sensitivity." When the visitor is on the defensive, it is almost impossible for him to maintain an open mind. If he feels that either he himself or his country is being misunderstood and unfairly criticized, he is obliged to put up a defense; he cannot afford to admit the truth or half-truth which may be couched in the criticism.

The complement of defensiveness about one's own country is disparagement of the other country. One might hypothesize some kind of rough equivalence here: the more one feels that his own country is at a disadvantage, the more he feels compelled to attack the other country. Conventional stereotypes guide both the attack and the defense. The Germans criticized Americans for being materialistic, superficial, and politically naïve. Americans might have reciprocated by condemning German authoritarianism. The interesting thing for us is that these well-established criticisms of one nationality group by another did not seem to change as a result of cross-cultural contact. Rather, they seemed to be confirmed.

We are inclined to explain this by assuming that visiting this country made it possible, for example, for the Germans to confirm the fact that Americans were rich in material goods, but it did not stimulate any new 
ideas about how to interpret this fact. The visitors did not learn much about what the possession of material wealth meant to Americans, because they were too thoroughly committed to the evaluation of American materialism which had been developed in Germany by Germans.

Perhaps a clearer example of the way in which differences in national culture can set up road blocks to communication comes from our experience in trying to offer the Germans training in group dynamics. There were many difficulties in this program, but one of the central issues grew out of contradictory interpretations of what it meant for us to ask the visitors to make decisions as a group.

To the Germans, this request seemed to mean that we were denying their individuality. They recognized only two alternatives, namely, that we treat them separately as individuals or that they submerge their individuality in the group. They pointed out that they were too different from each other to work as a group. For us, on the other hand, the request for group decisions represented an attempt to set up a procedure which would help us to meet individual needs. The paradoxical thing was that both the Americans and the Germans were working for the same ends. They disagreed only about means. However, the fact that the same word, group, was used positively by one nationality group and negatively by the other made it impossible for the two groups to communicate with each other. The very mention of the word group came to be a red flag which would mobilize hostilities on both sides.

Our comments so far have focused upon some of the ways in which the reactions of visitors to a foreign country are governed by the culture of the country from which they come. We have said that cross-cultural learning is facilitated when the two countries have values in common or when one country defines the other as a legitimate source of expert knowledge. On the other hand, cross-cultural learning is blocked when either visitors or hosts are put on the defensive or when the symbolic terms which members of one culture use to define their positive and negative values are assigned different and incompatible meanings in the other culture. To put it differently, learning is facilitated when the host country has some contribution to make to the maximization of the visitors' values, and learning is blocked in areas where the values of the host country are incompatible with, or threatening to, the values of the visitors. This general line of analysis would seem to imply that continuity is more important than change; that individuals who travel abroad learn the things which their culture has prepared them to learn, and not anything else.

A similar argument can be made for the continuity of personality. Researchers who have studied personality differences are able to show that people react to cross-cultural experience in ways which are personally consistent. Foreign visitors see what they are prepared to see, and the amount of change or non-change which results from their trip abroad can be predicted from personality characteristics.

It should be pointed out, however, that there is an important methodological problem here. In our roles as social scientists we are obliged to look for continuities, for consistencies, for predictable regularities. The design of our research often forces us to view change either as a natural extension of some already existing point of view or as unpredictable error. In neither case do we obtain information which will allow us to develop a theory of change. Yet one' of the things which we want to learn from studies of cross-cultural experience is whether such experience acts consistently as a force toward change, regardless of the self-perpetu- 
ating nature of culture and personality. We think that it does, and we think that we can say something about what kind of change it produces, as well as something about the process by which change occurs.

First, then, there seems to be good evidence that exposure to a different pattern of values can bring about some value change on the part of the visitors. This is particularly true if the host culture can offer new resolutions of value conflicts which the visitors bring with them or new ways of implementing values which are important to the visitors but which are not adequately realized in their own culture.

In our study, the value pattern which most interested us was, of course, commitment to democracy. We computed two indexes, one of which reflected explicit positive comments about values and procedures which the respondent identified as democratic and the other reflected internalized commitment to values which we called democratic but which the respondent did not label as such. These values included things like tolerance, civic responsibility, and "give-and-take" in interaction. We found that explicit indorsement of democracy was highest at the time of departure and dropped after return, but that internalized commitment to democratic values increased both in this country and again after return to Germany.

Second, it seems fairly clear that crosscultural experience leads to greater internationalism. The German visitors gave many indications that such a change had occurred. They reported directly that they had become more cosmopolitan. In their discussions of world affairs, they demonstrated that they had moved away from a nationalistic view and toward internationalism. This was true both for the ideas which they indorsed directly and for the implicit criteria which they used to evaluate actions of Germany and the United States.
It appears that these changes must be located within the context of time and space. It is clear that the shift toward greater internationalism took place within the context of geographical space. It was associated with high commitment to the United States when the visitors were still in this country and with high commitment to Europe after they returned home. In addition, it is interesting to note that the time at which the visitors were most likely to report that they had gained increased perspective on Germany was just before they left the United States.

Attitudinal change must be understood also in terms of a framework of time. We identified four sequential phases which seemed to be important in describing the process of attitude change.

First, there is the initial period during which the visitor approaches the new country from behind the barriers provided by his culture and his personality. This is a period of stereotypes and also of polarities. Differences between the visitors' country and the host country tend to be defined in terms of black and white. During this period the Germans were saying overtly that their country was superior, while indirect evidence indicated that they actually saw America as superior and Germany as inferior.

The second period begins when the need for defensive or stereotyped perception begins to diminish and the visitor for the first time allows himself to be exposed to the foreign culture as it actually exists. During this period he acquires new ideas and points of view, but he refrains from making any personal commitment to them.

The third period involves the reorganization of existing patterns of belief and value to incorporate new ideas and perspectives. Our scanty evidence suggests that it is best if this period of reorganization occurs after the visitor returns home. He should stay in 
the foreign culture long enough to get through the first period of stereotyped interaction and into the second period of receiving new impressions, but his assimilation of these new impressions should take place at home, where he can keep in touch with his own culture.

The last period in the change sequence is the period of testing and consolidation, during which the revised pattern of values and beliefs is tested for suitability in the lifesituation of the individual. If the new pattern has been worked out in the culture where it will be used, it is likely to prove satisfactory, and change which began during the period of travel can be consolidated and expanded for some time after return home. Thus, for example, we found that visitors who had been in the United States for twelve months had a much harder time readjusting to Germany than those who had been here for only six months. Changes which had been made in the United States were likely to be extended by the six-month visitors and reversed by the twelve-month visitors.

This sequential view of change has some interesting implications for evaluation research. It would suggest that measures of change taken at time of departure are very unreliable indexes of what will follow. A person who shows a great deal of change at time of departure may not be able to sustain the change after he gets home. On the other hand, a person who has collected a lot of new ideas but has not yet really assimilated them may look like a non-changer at time of departure and yet, in the long run, may turn out to be one of the people who change the most.

One last point should be made about cross-cultural experience as a source of attitude change, and this is that alienation can and does occur. It is quite possible for exposure to a foreign culture to move a person so far out of his own culture that he cannot go home again. Our experience, however, was that exposure to a foreign culture was more likely to give a person new perspectives on his own culture, without seriously alienating him from it.

Most of the Germans whom we interviewed in Germany six months after their return home indicated that they had found some difficulty in readjusting to the world they had left behind. Their first impressions when they arrived home were often negative. Later, they became restless; they changed jobs or thought about doing so; they developed new ideas about what kind of careers they would like for themselves. Also, the follow-up interviews were the ones in which respondents were most likely to say that they felt different from other Germans or felt that other Germans would not agree with beliefs which they had expressed about Germany or the United States or world affairs. In the majority of cases, however, this increased sense of distance was not accompanied by any disaffection. The returned visitors still felt loyal to Germany and wanted to live and work in Germany.

On the other hand, there were some exceptions to this. Ten per cent of the persons in our study had emigrated from Germany before the follow-up interviews took place. We know of another 10 per cent who have left Germany since that time, and there may be still others whom we do not know about who have also left Germany. Interviews with the people still in Germany showed a sharp rise after returning home in interest in the diplomatic service. This seemed to be one of the few techniques by which they could both serve Germany and leave Germany.

In any discussion of alienation, we must recognize that selection may be as important as travel. The person who chooses to come to America in the first place may already be looking for ways to break with 
traditional national patterns. However, probably it would be a mistake to attribute post-travel restlessness and alienation entirely to selection. Travel in itself, by exposing persons to alternative ways of thinking and living, leads them to ask new questions and develop new hopes and aspirations. At first, they may try to find new solutions for themselves within the boundaries of their own culture. However, if this does not work, they may take the more drastic step of emigrating to another country, to try and make better lives for themselves elsewhere.

In summary, then, we can conclude that cross-cultural experience does generate predictable kinds of attitude change. Strong support is given to cosmopolitan values and to the salient values of the host country.
The visitor responds to these pressures in the context of his own culture and personality and also in the context of time and space. Sometimes he will change so much that it becomes difficult or impossible for him to return home. In the case of the German visitors, however, the visit to America was more likely to stimulate efforts to improve things at home than to create lasting alienation from Germany.

\section{REFERENCES}

1. Lambert, R., and Bressler, M. Indian Students on an American Campus. Minneapolis: University of Minnesota Press, 1956.

2. Watson, JeANNE, and LippitT, R. Learning across Cultures. Ann Arbor: University of Michigan Press, 1955. 